\title{
STUDIES ON MINERAL DUST USING AIRBORNE LIDAR, GROUND-BASED REMOTE SENSING, AND IN SITU INSTRUMENTATION
}

\author{
Franco Marenco ${ }^{*}$, Claire Ryder ${ }^{2}$, Victor Estellés ${ }^{3}$, Sara Segura $^{3}$, Vassilis Amiridis ${ }^{4}$, \\ Emmanouil Proestakis ${ }^{4}$, Eleni Marinou ${ }^{4}$, Alexandra Tsekeri ${ }^{4}$, Helen Smith $^{5}$, Zbigniew Ulanowski ${ }^{5}$, \\ Debbie O'Sullivan', Jennifer Brooke ${ }^{1}$, Yaswant Pradhan', and Joelle Buxmann ${ }^{1}$

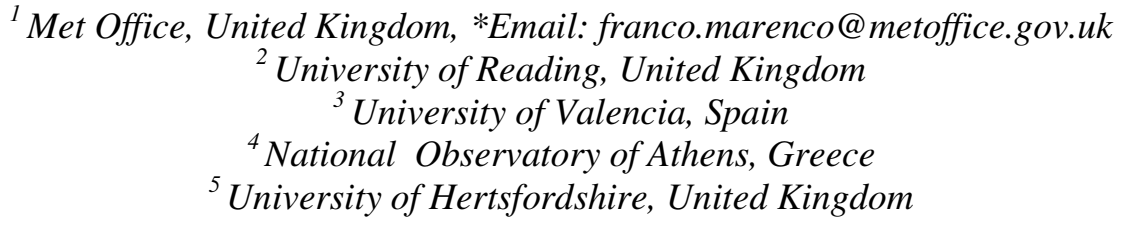

\begin{abstract}
In August 2015, the AER-D campaign made use of the FAAM research aircraft based in Cape Verde, and targeted mineral dust. First results will be shown here. The campaign had multiple objectives: (1) lidar dust mapping for the validation of satellite and model products; (2) validation of sunphotometer remote sensing with airborne measurements; (3) coordinated measurements with the CATS lidar on the ISS; (4) radiative closure studies; and (5) the validation of a new model of dustsonde.
\end{abstract}

\section{INTRODUCTION}

From 6 to 25 August 2015, the FAAM BAe-146 research aircraft was based in Praia on the Santiago island (Cape Verde). A ground-based site with several types of instruments was established at the base airport, including two sunphotometers (PREDE-POM01 and CIMEL CE318-NEDPS9 dual-polarization). Additional sun-photometer measurements were available through the permanent AERONET station Cabo Verde in Sal Island. A number of dustsondes of a new type [1] were also launched from Sal.

In this season, mineral dust transport from the Sahara is frequent (see Figure 1). Sixteen research flights were carried out, 10 of which targeted the role of dust as primary heterogeneous ice nuclei (ICE-D campaign). Six more flights, described in this paper and listed in Table 1,
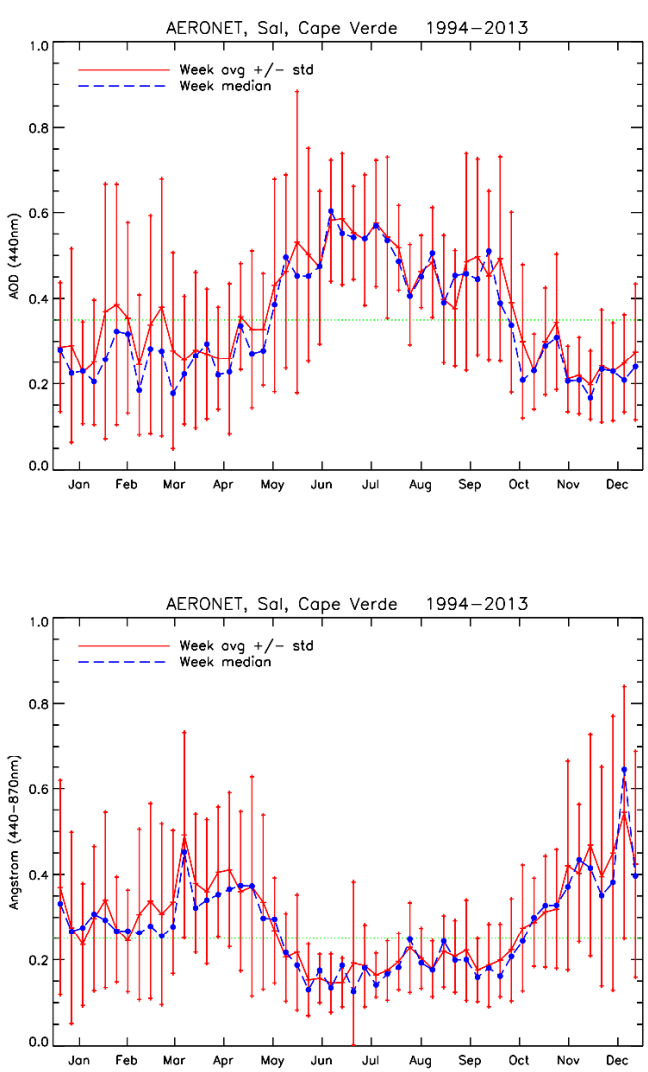

Figure 1. Yearly cycle of aerosol optical depth and Angstrom exponent, as derived from 20 years AERONET observations (1994-2013) at Sal, Cape Verde. 


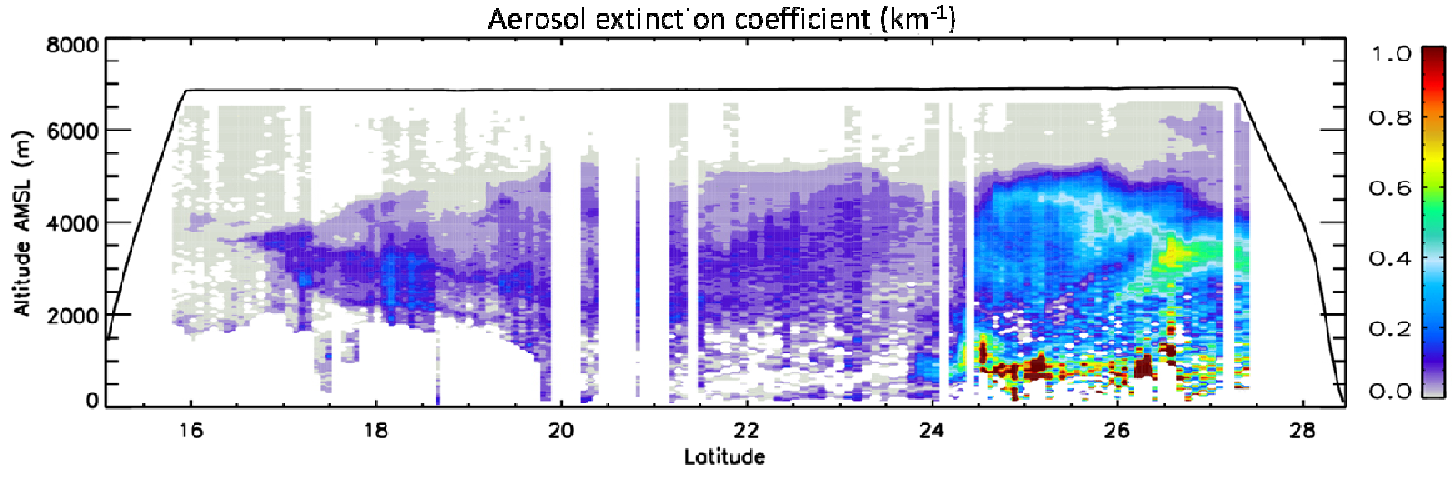

Figure 2. Aerosol extinction coefficient measured by airborne lidar in flight B923( flight from Cape Verde to the Canary Islands).

aimed at a series of objectives in the field of aerosol science and remote sensing (AER-D campaign). The aims of AER-D were multiple: (1) lidar dust mapping for the validation of satellite and model products; (2) validation of sunphotometer remote sensing with airborne measurements; (3) coordinated measurements with the CATS lidar on the ISS; (4) radiative closure studies; and (5) the validation of a new model of dustsonde.

Table 1. Summary of the AER-D research flights

\begin{tabular}{|l|l|l|}
\hline B920 & 7 Aug. & CATS underflight \\
\hline B923 & 12 Aug. & Dust mapping \\
\hline B924 & 12 Aug. & Dust mapping \\
\hline B928 & 16 Aug. & SAVEX-D (Santiago) \\
\hline B932 & 20 Aug. & Dust mapping \\
\hline B934 & 25 Aug. & SAVEX-D (Sal) \\
\hline
\end{tabular}

\section{LIDAR SYSTEM}

The aircraft carried a nadir-pointing ALS450 elastic backscatter lidar, operating at $355 \mathrm{~nm}$, manufactured by Leosphere. Signal inversion to aerosol extinction coefficient is done following reference [2].

\section{DUST MAPPING}

The dust mapping flights were designed to map the spatial distribution and vertical structure of the dust layer with the on-board lidar, by flying at high altitude over a long distance. Our main goal is the development of a dust product based on SEVIRI, based on infrared channels and a 1DVAR retrieval scheme [3], and these flights will yield a good opportunity for its validation. We anticipate also other comparisons, such as e.g. with the Met Office Unified Model dust prediction.

On 12 August the advection of a a large dust load was predicted over the Canary islands, and a double flight was carried out with a refuel at Fuerteventura, and on 20 August the experiment was repeated but with a shorter, single flight towards the Northern border of Mauritania on the coast. Figure 2 shows the cross-section of the dust extinction coefficient determined with the airborne lidar during the first of these flights. Whereas the flight starts with little or no dust near Cape Verde, the dust layer is seen to increase in depth initially, and then in optical depth. North of $24 \mathrm{~N}$, a dust "front" is encountered and its structure is mapped. This "front" is clearly identifiable in the visible and infrared satellite imagery. A similar pattern is observed in flights B924 and B932. Small sections of the mapping flights were also devoted to in situ measurements, by bringing the aircraft down into the dust layer, and they revealed very large particles (up to $\sim 100$ $\mu \mathrm{m}$ in diameter). The AOD in the high dust region reached $\sim 2$, approaching the limits of the lidar system itself due to the large signal extinction.

\section{CATS UNDERFLIGHT and SAVEX-D}

The first of our flights was aimed at a comparison of aircraft measurements to observations from the CATS lidar on board the International Space Station. This is a backscatter lidar operating at $1064 \mathrm{~nm}$ and $532 \mathrm{~nm}$, launched in 2015, and with a processing chain similar to CALIOP's [4]. The aim of the SAVEX-D flights, instead, was the 

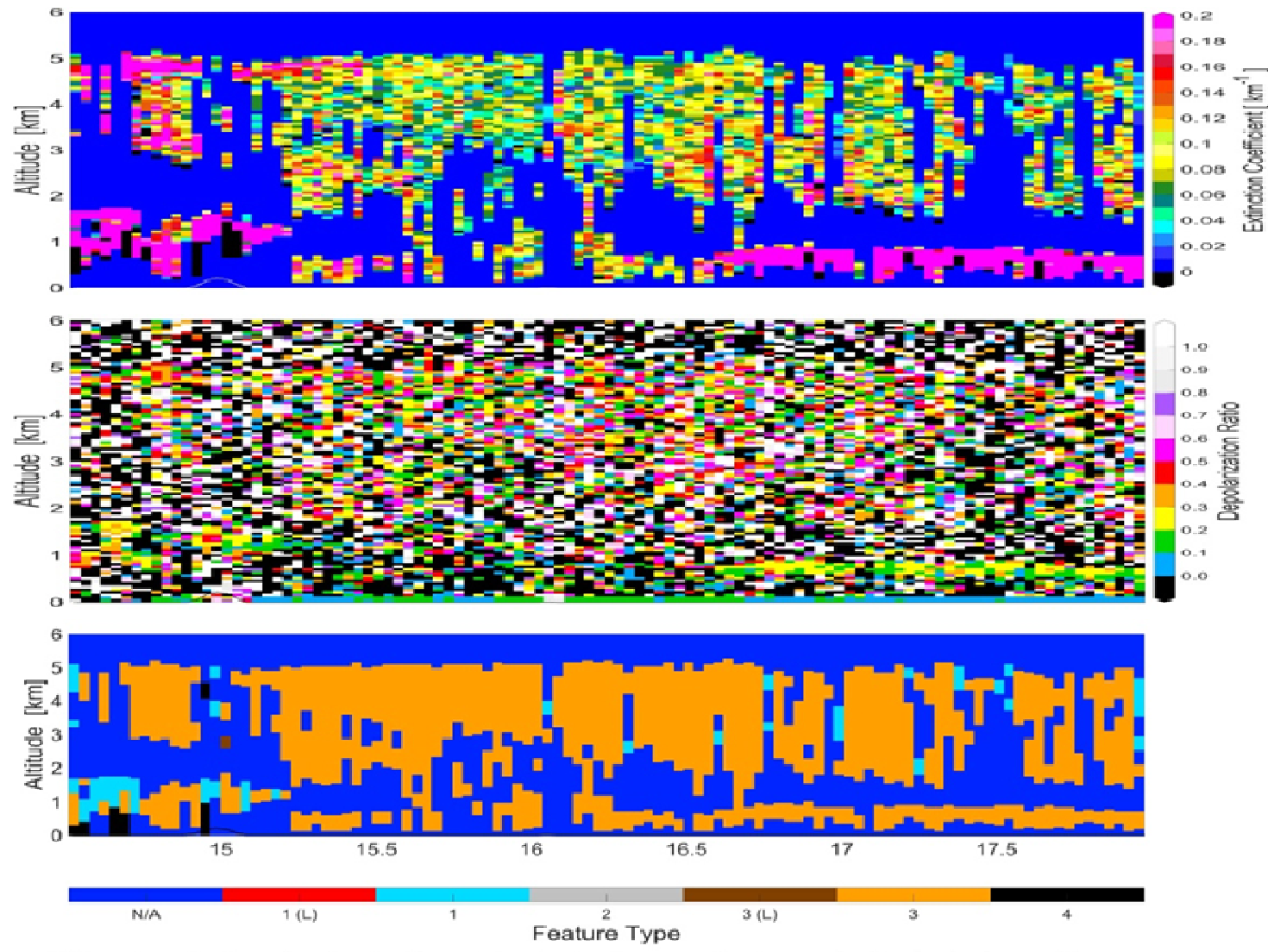

N/A = not applicable $\quad 1$ = cloud $\quad 2$ = undetermined $\quad 3$ = aerósol $\quad 4$ = nó signala $L$ L low/nó cónfidence
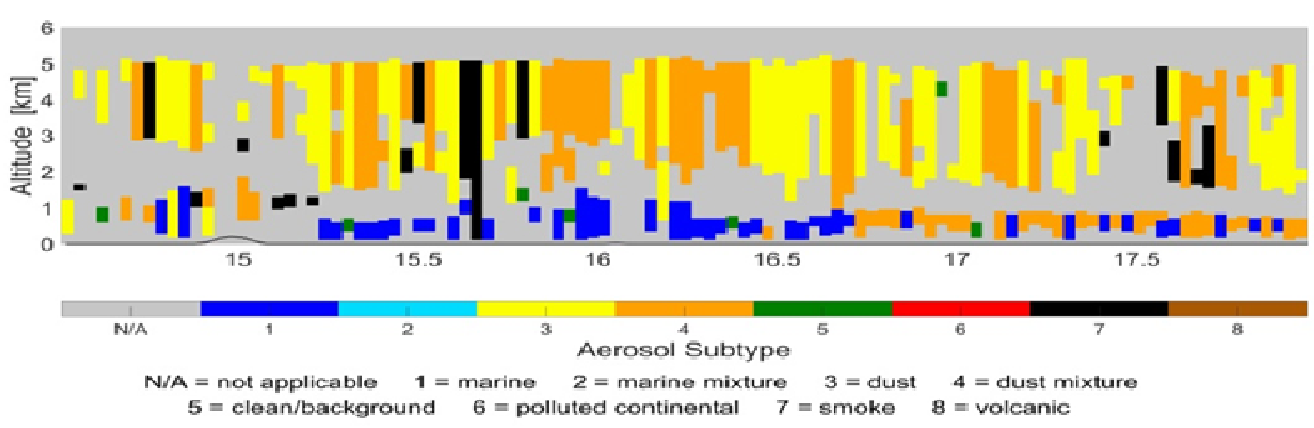

Aerosol extinction coemiclent $\left(\mathrm{km}^{-1}\right)$

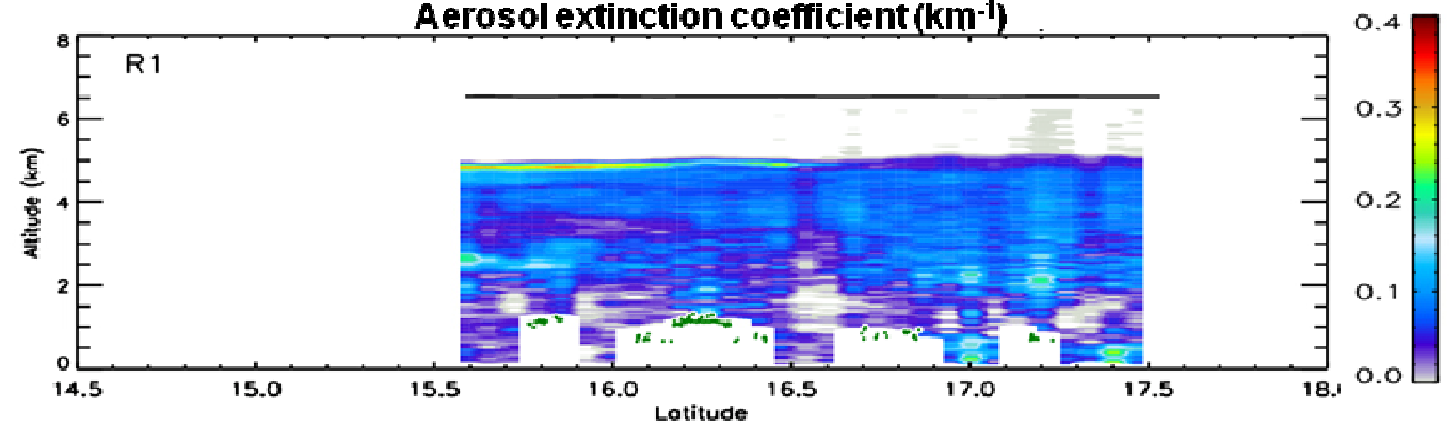

Figure 3. Flight B920 overview (CATS underflight). From top to bottom: CATS extinction coefficient, CATS depolarization ratio, CATS feature type, CATS aerosol mask, and airborne lidar extinction coefficient. 
validation of SKYNET and AERONET groundbased sunphotometer retrievals of columnar aerosol microphysical properties, and in particular the size-distribution [5]. The track for these flights was confined within a small area, and the airplane sampled the atmosphere at a series of levels within the dust layer (to measure in situ properties) as well as above (to provide a lidar overview of the scene). As an example, Figure 3 compares the CATS L2 products with the scene depicted by the airborne lidar, showing great consistency.

\section{RADIATIVE CLOSURE, DUST PROPERTIES, AND NEW MODEL DUSTSONDES}

In this presentation, we will also show first results concerning our radiative closure studies, the detailed characterization of dust properties, and the comparison of the airborne data with the new dustsondes.

\section{CONCLUSIONS}

AER-D has been a very successful campaign, despite relying on a small number of flights. The measurements provide insight on the vertical structure of the Saharan Air Layer and on its microphysical properties; they provide a small but detailed dataset on the dust spatial distribution, designed for satellite and modeling cal/val exercises; and they provide in situ and remote sensing information for the validation of CATS retrievals, sunphotometer retrievals, and the measurements from the new model of dust sondes.

The data analysis is still preliminary at this stage but progress is being made quickly and we anticipate a number of publications in the years to come.

\section{ACKNOWLEDGEMENTS}

Airborne data was obtained using the BAe-146 Atmospheric Research Aircraft flown by Directflight Ltd. and managed by the Facility for Airborne Atmospheric Measurements (FAAM), which a joint entity of the Natural Environment Research Council (NERC) and the Met Office. R. Cotton, T. Choularton, M. Gallagher, K. Bower, J. Taylor, J. Crosier, G. Lloyd, D. Lui, P. Rosenberg, J. McQuaid, B. Murray, H. Price,
FAAM, and the full team taking part in the ICE-D campaign are gratefully acknowledged for their assistance and the provision of datasets. The SAVEX-D project and the participation of Sara Segura and Victor Estellés were possible thanks to EUFAR TNA (European Union Seventh Framework Programme grant agreement 312609) and projects PROMETEUII/2014/058 and GV/2014/046 from the Valencia Autonomous Government. Copernicus Atmosphere Monitoring Services and ECMWF are gratefully acknowledged for the provision of forecast products used for flight planning. Axel Wellpott is thanked for his help in predicting the ISS orbit and other satellites for flight planning. We thank Didier Tanré for the effort in establishing and maintaining the Sal AERONET station. John Yorks, Ed Nowottnick, and NASA are kindly thanked for their assistance during the campaign and for the provision of CATS data.

\section{References}

[1] Smith, H.R., J. Ulanowski, P. Kaye, E. Hirst, W. Stanley, and A. Weiser, 2016: A Universal Cloud and Aerosol Sounding System (UCASS) based on wide angle light scattering, presented at the Focus Meeting on Recent Advances in Aerosol Measurement Technology, Aerosol Society, 5 April 2016.

[2] Marenco, F., Nadir airborne lidar observations of deep aerosol layers, Atmos. Meas. Tech. 6, 2055-2064, 2013

[3] Francis, P.N., M.C. Cooke, and R.W. Saunders, 2012: Retrieval of physical properties of volcanic ash using Meteosat: A case study from the 2010 Eyjafjallajökull eruption, J. Geophys. Res. 117, doi:10.1029/2011JD016788.

[4] Yorks, J.E., M.J. McGill, S.P. Palm, D.L. Hlavka, P.A. Selmer, E P. Nowottnick, M.A. Vaughan, S.D. Rodier, and W.D. Hart, 2016: An overview of the CATS level 1 processing algorithms and data products, Geophys. Res. Lett. 43, 4632-4639.

[5] Estellés, V., Campanelli, M., Utrillas, M.P., Expósito, F., and Martínez-Lozano, J.A., 2012: Comparison of AERONET and SKYRAD4.2 inversion products retrieved from a Cimel CE318 sunphotometer, Atmos. Meas. Tech. 5, 569-579. 